Origical Article

\title{
Diagnostic value of Breast Specific Gamma Imaging with semi- quantitative index (T/N) in Breast Cancer Diagnosis
}

\author{
Dipendra Kumar Mallik², Wei Zhang Hong², Wei Zhu², Ge Yang Wei², Lei Shen², Fu Hu Guang', Ganga Sapkota ${ }^{1}$ \\ ${ }^{1}$ GI-Breast Surgical Oncology Unit, B.P.Koirala Memorial Cancer Hospital, Bharatpur, Nepal. \\ ${ }^{2}$ Breast surgical unit, Department of General Surgery, Fudan University Zhongshan Hospital, Shanghai, China
}

\begin{abstract}
Objective: The study in this part was to evaluate the diagnostic value of Breast Specific Gamma Imaging (BSGI) by semi-quantitative method for detection of breast cancer.

Methods: 400 patients with indeterminate breast tumors that underwent BSGI were enrolled in this study. All included lesions were confirmed by postoperative pathology. BSGI evaluation was based on the visual interpretation and semi-quantitative parameters of the higher tumor to non-lesion $(T / N)$ value of $C C$ and MLO. Compared with pathological results, the optimal visual analysis and the value of $\mathrm{T} / \mathrm{N}$ were calculated through $\mathrm{ROC}$ curve analysis. Independent t-test and Pearson linear correlation were applied for statistical analysis.

Results: Tumor to non-lesion (T/N) ratio was available for 279 out of 400 patients. This population comprised 203 patients with malignant and 74 patients with benign lesion. ROC analysis showed critical value of $\mathrm{T} / \mathrm{N}=1.91$, AUC is 0.83 (standard error $=0.014,95 \%$ confidence interval); BSGI sensitivity is $83.71 \%$ and specificity is $76 \%$. $\mathrm{T} / \mathrm{N}$ ratio for invasive and non-invasive cancers are $2.70 \pm 0.88$, and $2.09 \pm 0.44$ respectively; the difference between two have statistical significance $(t=3.32, \mathrm{P}=0.001)$. Infiltrating ductal carcinoma (IDC) grade I, grade II, and grade III have $\mathrm{T} / \mathrm{N}$ ratio of $2.33 \pm 0.94,2.38 \pm 0.80,2.89 \pm 0.89$ respectively. The $\mathrm{T} / \mathrm{N}$ differences between grade I and grade II have no statistical significance $(t=0.12, P=0.89)$. The $T / N$ differences between grade I and grade III have no statistical significance $(t=1.56, P=0.12)$. The $T / N$ differences between grade II and grade III have statistical significance $(t=3.69, P<0.001) . T / N$ value for tumor size $<1 \mathrm{~cm}$ and $>1 \mathrm{~cm}$ were $1.97 \pm 0.79$ and $2.46 \pm 0.88$ respectively; the difference between two have statistical significance $(t=3.27, P=0.001)$.

Conclusion: The semi-quantitative index of $\mathrm{T} / \mathrm{N}$ correlates with clinico-pathological characteristics of tumor like: size, grade, and invasiveness of breast cancer, and at certain level can be helpful to determine patient's prognosis.
\end{abstract}

Keywords: Breast Cancer, Breast specific gamma imaging, Diagnosis

\section{Introduction}

Breast cancer has long been recognized as one of the common malignancy among women in developed and developing countries. Recently, global incidence of breast cancer has increased rapidly, and portrays the tendency to be a crucial cause of mortality in women of reproductive age ${ }^{(1)}$. Early detection, early diagnosis and timely treatment hold the key to improve the survival rate among breast cancer patients.

Mammography (MMG) is the only widely recognized first line radiologic examination used as a breast cancer screening method because of its high sensitivity and because it leads to reduced mortality ${ }^{(2)}$. One of the biggest advantages of mammography is its detection of micro-calcifications and soft-tissue densities (3). Hence, is recognized as "Gold Standard" for detection of Ductal Carcinoma In Situ (DCIS). But 10\% 15\% of
DCIS does not have micro-calcification. DCIS with noncalcification, dense breast DCIS and lesion attached with or close to chest wall are easily misdiagnosed by MMG ${ }^{(4-5)}$. The sensitivity of mammography can be limited in young women especially $<50$ years, with dense breast tissue. It might be due to the presence of overlapping fibro-glandular tissue, which reduces conspicuity of abnormalities ${ }^{(6)}$. Ultrasound (US) is another commonly used anatomic imaging procedures to detect breast cancer. It can detect small node-negative breast cancers, which increases the possibility of cancer diagnosis, especially in women with mammographically dense breast tissue; however, ultrasound also has a high falsepositive rate, and there have been concerns about its operator dependence ${ }^{(7-9)}$.

Molecular imaging technologies have been developed recently to circumvent limitations posed by other 
modalities for BC screening. It is not affected by radiodense breast tissue, breast implants, or unexplained architectural distortion, and can be used in patients whom MRI is indicated but not possible. Singlephoton Emission Computed Tomography (SPECT) uses conventional planar gamma camera, which makes it difficult to detect lesions of less than $10 \mathrm{~mm}$ due to excessive organ-to-detector distance as well as the difficulty to image in positions comparable to mammography. Recent advances in technology have resulted in the development of Breast Specific Gamma Imaging (BSGI) with highresolution gamma cameras and improved ability to image sub-centimeter cancers up to $3 \mathrm{~mm}$ diameter ${ }^{(16-18)}$. Hence, it has increased the sensitivity for screening and monitoring Breast Cancer. Brem et al. ${ }^{(18)}$ in 2002, successfully brought BSGI into clinical application.

99mTc sestamibi (99mTc-MIBI) is a non-specific tumor radiotracer, and its role in improving accuracy of breast cancer diagnosis is still being researched. Currently, BSGI image interpretation is mainly done by visual analysis method. According to the 2010 American Society of Nuclear Medicine (SNM) guideline ${ }^{(15)}$, the visual analyses grades of BSGI were as follows: Grade 1: no abnormal increased uptake in either early or delayed images, Grade 2: mildly increased uptake in the early image without retention in the delayed image, Grade 3: mildly increased uptake in the early image with retention in the delayed image, Grade 4: definite focal increased uptake in the early image without retention in the delayed image, and Grade 5: definite focal increased uptake in the early image with retention in the delayed image. Visual analysis is easily affected by subjective factors like patient's prandial state, by exercise, and by changes in peripheral blood flow etc. ${ }^{(19)}$. $99 \mathrm{mTc}$ sestamibi clearance in tumor tissue is slower than that of surrounding normal tissues, previous studies have demonstrated that BSGI image can help in improving tumor detection rate ${ }^{(20)}$.

In recent times, with the development of bio-molecular techniques, biological behavior of breast cancer at molecular level has been bought into light. It has found some related molecular index such as Estrogen Receptor (ER), Progesterone Receptor (PR), Human Epidermal Growth Factor Receptor 2 (Her-2), Nuclearassociated Antigen (Ki-67). With the help of these molecular markers, breast cancer can be divided into molecular subtypes. Thus, can help in further evaluation of prognosis, also can guide through clinical treatment selection.
Papantoniou et al. ${ }^{(10)}$, in retrospective analysis of 34 cases with histologically confirmed breast carcinoma who underwent preoperative scintimammography with administration of $925-1110 \mathrm{MBq}$ technetium-99m (99mTc)-(V) DMSA and/or 99mTc-MIBI, reported that there is no correlation between $\mathrm{T} / \mathrm{N}$ ratio with $\mathrm{ER}, \mathrm{PR}$, Her-2, Ki67, and tumor size was the only independent parameter influencing MIBI uptake in breast cancer. In a study by Cwikla et al. ${ }^{(5)}$, reported that semi-quantitative parameter $\mathrm{T} / \mathrm{N}$ (tumor to background) ratio of Scintimammography (SMM) has correlation some of the known prognostic factors of breast cancer such as tumor size and grade. Therefore, in this study we discuss about diagnostic value of Breast Specific Gamma Imaging with semi-quantitative index $(\mathrm{T} / \mathrm{N})$ in Breast Cancer Diagnosis. However, in our study, immunohistochemical (IHC) components such as ER, PR, Her-2 and Ki67 were not taken into consideration, as multicenter study might show more promising results on this aspect.

The BSGI mechanism depends on the tumor neoangiogenesis and abundant cytoplasmic mitochondria within the tumor cell. 99mTc-sestamibi when administered through an anticubital vein, it is distributed evenly to the circulatory system. Because of tumor neo-angiogenesis, tumor lesion is more enhanced. Whereas tumor cells have more abundant cytoplasmic mitochondria, $99 \mathrm{mTc}$-sestamibi specifically binds with cytoplasmic mitochondria. This means that $99 \mathrm{mTc}-$ sestamibi binds with tumor tissue more abundantly than with normal tissue ${ }^{(13,14)}$

\section{Materials \& Methods}

\section{Patients:}

A retrospective study approved by institution review board of Fudan University Zhongshan Hospital, Shanghai, China. The review of pathological records and image did not require patient approval or informed consent. A total of 422 patients underwent Breast Specific Gamma Imaging (BSGI), from July 2013 to June 2015 at our institution. 22 patients were excluded because of unavailable pathological report. Patients going through neo-adjuvant chemotherapy or radiotherapy, pregnancy, biopsy within 3 days before radiological examinations is excluded.

\section{Imaging Interpretations:}

\subsection{Apparatus and agents}

BSGI: Apparatus used is a high-resolution breastspecific gamma camera (Dilon 6800; Dilon Technologies, 
USA). Radioactive agent used is $99 \mathrm{mTc}$ - MIBI (99mTcsestamibi), Shanghai GMS Pharmaceutical Co., Ltd, Radiochemical purity $>95 \%$.

\subsection{Imaging methods}

BSGI imaging: Patient doesn't require any special preparation; patients were administered with 740925MBq (15-20mCi) Tc-99m-MIBI through an anticubital vein. Vein injection was taken in the contralateral arm of suspicious breast lesions to avoid false-positive uptake in the axillary lymph nodes. After 6-10 minutes, both breasts were imaged in cranio-caudal (CC) and mediolateral oblique (MLO) projections; similar with mammography position, Collection period is $6 \mathrm{~min}$ /position. Scanning parameters: Voltage $140 \mathrm{KeV}$, window width $10 \%$.

\section{Image analysis:}

\subsection{Visual analyses:}

BSGI images were analyzed and interpreted by two experienced Nuclear Medicine physicians who were blind to the patients' clinical information and pathology results. According to the 2010 American Society of Nuclear Medicine (SNM) guideline ${ }^{(15)}$, the visual analyses grades of BSGI were as follows: Grade 1: no abnormal increased uptake in either early or delayed images, Grade 2: mildly increased uptake in the early image without retention in the delayed image, Grade 3: mildly increased uptake in the early image with retention in the delayed image, Grade 4: definite focal increased uptake in the early image without retention in the delayed image, and Grade 5: definite focal increased uptake in the early image with retention in the delayed image.

3.2 Semi quantitative method:

The higher tumor to non-lesion $(\mathrm{T} / \mathrm{N})$ value of craniocaudal (CC) and mediolateral oblique (MLO) projections is taken as parameter for semi-quantitative analyses.

\section{Statistics:}

The imaging of BSGI, mammography and ultrasound is compared with the results of pathological diagnosis using SPSS version 16.

\section{Results}

\section{Clinical characteristics}

During the study period, a total number of 400 patients underwent BSGI. This population comprised 243 patients with malignancy and 157 patients with benign lesions.
For the malignant group, the histology confirmed 243 patients were with 245 malignant lesions, including 241 patients with single mass, 2 patients with 2 lesions. The distribution of post-surgery pathology were invasive ductal carcinoma (IDC), 185(76.13\%); invasive lobular carcinoma (ILC), 5(2.05\%); ductal carcinoma in situ (DCIS), 35 (14.40\%); Paget's disease, 1 (0.41\%); Mixed carcinoma, 4 (1.64\%), and others (Neuroendocrine carcinoma in situ, Mucinous Carcinoma, Intraductal papillary carcinoma, Metastatic poorly differentiated carcinoma), 13 (5.34\%). Among benign group, the mean age of 157 patients was $49.29 \pm 10.71$. Post-surgical histology confirmed these 157 cases were with 189 lesions, which contained 134 patients with single mass, 20 patients ( 8 with tumor on same side of breast, 12 with tumor on bilateral breast) with 2 lesions; and 5 patients with 3 lesions.

Table 1: Malignant tumor cases with available $\mathrm{T} / \mathrm{N}$ ratio

\begin{tabular}{|l|l|}
\hline \multicolumn{1}{|c|}{ Pathology } & \multicolumn{1}{c|}{ Number $(\mathbf{n = 2 0 3 )}$} \\
\hline Infiltrating ductal carcinoma & 160 \\
\hline Ductal carcinoma in situ & 29 \\
\hline Infiltrating lobular carcinoma & 5 \\
\hline Mixed carcinoma & 3 \\
\hline Paget's disease & 1 \\
\hline Others & 6 \\
\hline
\end{tabular}

Table 2: Benign tumors cases with available $\mathrm{T} / \mathrm{N}$ value:

\begin{tabular}{|l|l|}
\hline PATHOLOGY & NUMBER ( $=74$ lesions) \\
\hline Fibroadenoma & 32 \\
\hline Adenosis & 23 \\
\hline Intraductal papilloma & 10 \\
\hline Duct ectasia & 1 \\
\hline Chronic inflammation & 4 \\
\hline Benign Phyllodes & 1 \\
\hline Others & 3 \\
\hline
\end{tabular}

Tumor to non-lesion (T/N) ratio was available for 279 out of 400 patients. This population comprised 203 patients with malignant and 74 patients with benign lesion. Among the malignant group (Table 1) the distribution of post-surgery pathology were infiltrating ductal carcinoma (IDC), 160; ductal carcinoma in situ (DCIS), 29; infiltrating lobular carcinoma (ILC), 5; Mixed infiltrating ductal and infiltrating lobular carcinoma, 3; Paget's disease, 1; and others (Mucinous Carcinoma), 6. 
Among benign group (Table 2), post-surgical histology confirmed 32 patients with fibroadenoma, 23 with adenosis, 10 with intraductal papilloma, 4 with chronic inflammation, 1 with duct ectasia, 1 with benign phyllodes, and 3 with others.

\section{False negative and false positive:}

There were 41 false negative BSGI cases, out of which 24 were available with tumor to non-lesion ratio $(\mathrm{T} / \mathrm{N})$. This population comprises of Infiltrating ductal carcinoma (IDC), 17; Ductal carcinoma in situ (DCIS), 5; Infiltrating lobular carcinoma (ILC), 1; and Mixed infiltrating ductal and infiltrating lobular carcinoma, 1. Seventeen out of total 38 BSGI false positive cases were available with $\mathrm{T} / \mathrm{N}$ ratio. It includes Fibroadenoma, 6; Adenosis, 3; Intraductal papilloma, 2; Chronic inflammation, 2; Benign phyllodes, 1; and others, 3.

\section{Correlation between tumor size and $\mathrm{T} / \mathrm{N}$ ratio for} all available cases:

Table:3

\begin{tabular}{|c|c|c|c|c|c|c|}
\hline 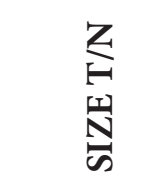 & $\begin{array}{l}\tilde{D} \\
\text { N̦ } \\
\stackrel{\nabla}{\mathrm{V}}\end{array}$ & 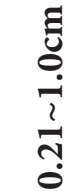 & 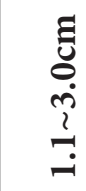 & 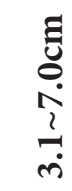 & 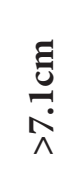 & 嵌 \\
\hline $1 \sim 2$ & 1 & 25 & 78 & 12 & 2 & 118 \\
\hline $2.01 \sim 3$ & 2 & 8 & 69 & 21 & 1 & 101 \\
\hline $3.01 \sim 4$ & 0 & 2 & 29 & 10 & 0 & 41 \\
\hline $4.01 \sim 5$ & 0 & 0 & 12 & 4 & 0 & 16 \\
\hline $5.01 \sim 6$ & 0 & 1 & 0 & 1 & 1 & 3 \\
\hline TOTAL & 3 & 36 & 188 & 48 & 4 & 279 \\
\hline
\end{tabular}

Correlation between tumor to non-lesion $(\mathrm{T} / \mathrm{N})$ ratio and tumor size, grade, and invasiveness is shown in Table 3 , fig. 1 , fig. 2 , fig. 3 , and fig. 4 . $\mathrm{T} / \mathrm{N}$ ratio for invasive and non-invasive cancers are $2.70 \pm 0.88$, and $2.09 \pm 0.44$ respectively; the difference between two have statistical significance ( $\mathrm{t}=3.32, \mathrm{P}=0.001)$ (Fig.1); Infiltrating ductal carcinoma (IDC) grade I, grade II, and grade III have $\mathrm{T} / \mathrm{N}$ ratio of $2.33 \pm 0.94,2.38 \pm 0.80,2.89 \pm 0.89$ respectively. The $\mathrm{T} / \mathrm{N}$ differences between grade I and grade II have no statistical significance ( $\mathrm{t}=0.12, \mathrm{P}=0.89$ ) (Fig.2). The $\mathrm{T} / \mathrm{N}$ differences between grade I and grade III have no statistical significance $(\mathrm{t}=1.56, \mathrm{P}=0.12)$ (Fig.3). The $\mathrm{T} / \mathrm{N}$ differences between grade II and grade III have statistical significance $(\mathrm{t}=3.69, \mathrm{P}<0.001)$ (Fig.4). $\mathrm{T} / \mathrm{N}$ value for tumor size $<1 \mathrm{~cm}$ and $>1 \mathrm{~cm}$ were $1.97 \pm 0.79$ and $2.46 \pm 0.88$ respectively; the difference between two have statistical significance $(\mathrm{t}=3.27, \mathrm{P}=0.001)$ (Table 3$)$.

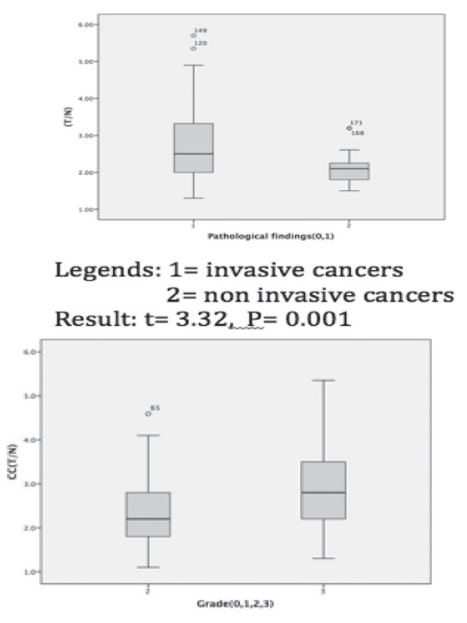

Fig.1 invasive vs non-invasive Fig.2 grade I vs grade II
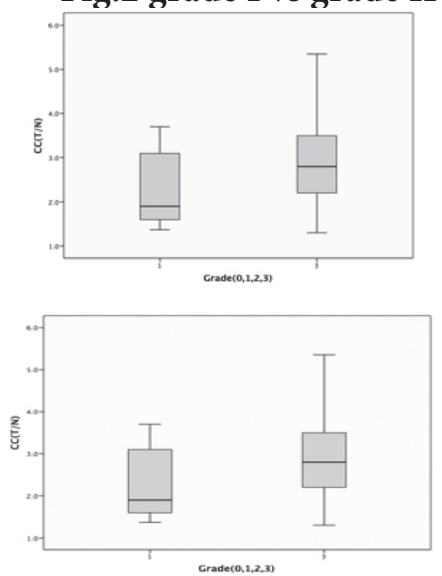

Fig. 3 grade I vs grade III Fig.4 grade II vs grade III

4. BSGI semi-quantitative parameter analysis ROC curve ROC analysis showed critical value of $\mathrm{T} / \mathrm{N}=1.91$, AUC is 0.83 (standard error $=0.014,95 \%$ confidence interval); BSGI sensitivity is $83.71 \%$ and specificity is $76 \%$.

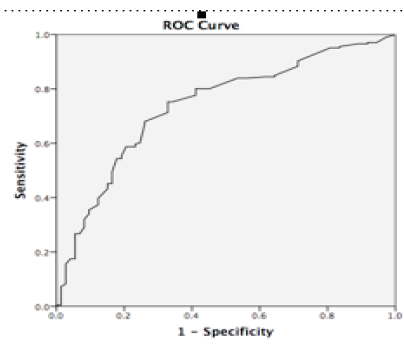


Fig. 5: semi-quantitative parameter analysis ROC curve Discussion:

Mammography and ultrasound is widely recognized anatomic breast imaging methods for screening of breast cancer (BC) in asymptomatic patients. Nuclear medicine breast imaging is a functional imaging method, and is increasingly being adopted into clinical practice. Scintimammography (SM), which primarily uses the radiopharmaceuticals $99 \mathrm{mTc}$-sestamibi, and $99 \mathrm{mTc}-$ tetrofosmin and PET imaging has demonstrated good results in clinical studies, but they have limitations when it comes for detection of breast cancer lesion less than $1 \mathrm{~cm}$. However, BSGI with high-resolution gamma cameras has improved ability to image sub-centimeter cancers up to $3 \mathrm{~mm}$ diameter, and is not effected with dense breast tissue, breast implants, or unexplained architectural distortion.

The BSGI mechanism depends on the tumor neoangiogenesis and abundant cytoplasmic mitochondria within the tumor cell. This means that 99mTc-sestamibi bindswith tumortissue moreabundantly than with normal tissue. ${ }^{(14)}$ Papantoniou et al. ${ }^{(10)}$ in retrospective analysis of 34 cases with histologically confirmed breast carcinoma who underwent preoperative scintimammography with administration of 925-1110 MBq technetium-99m (99mTc)-(V) DMSA and/or 99mTc-MIBI, reported that there is no correlation between $\mathrm{T} / \mathrm{N}$ ratio with $\mathrm{ER}, \mathrm{PR}$, Her-2, Ki67, and tumor size was the only independent parameter influencing MIBI uptake in breast cancer. In our study, immunohistochemical(IHC) components such as ER, PR, Her-2 and Ki67 were not taken into consideration, as multi-center study might show more promising results on this aspect. However, our study suggests BSGI semi-quantitative parameter $\mathrm{T} / \mathrm{N}$ ratio has correlation with invasiveness, tumor size and grade. Breast malignant tumor size, pathologic grade and invasiveness are closely related with prognosis of patient. Generally, larger is the tumor size, higher is its pathologic grade, and during axillary lymph node metastasis patient shows relatively poor prognosis. In a study by Cwikla et al., reported that semi-quantitative parameter $\mathrm{T} / \mathrm{N}$ (tumor to background) ratio of Scintimammography (SMM) has correlation some of the known prognostic factors of breast cancer such as tumor size and grade. ${ }^{(11)}$ In a retrospective study by Tadwalkar et al., 139 female patients with invasive carcinoma who underwent BSGI were reviewed. They reported that all cancers of grade 2 or 3 were detected with BSGI, regardless of size, and all cancers, whether they were grade 1,2 or 3 , were detected with BSGI if they were $>7 \mathrm{~mm} .{ }^{(12)}$ Hence, it suggests that the effectiveness of BSGI in diagnosis of breast carcinoma is related with tumor size and grade. In our study, $\mathrm{T} / \mathrm{N}$ value for tumor size $>1 \mathrm{~cm}$ is greater than that of tumor size $<1 \mathrm{~cm}$; the difference between two have statistical significance $(\mathrm{t}=3.27, \mathrm{P}=0.001)$. Hence, it suggests there is correlation between tumor size and $\mathrm{T} / \mathrm{N}$ value $(\mathrm{r}=0.152, \mathrm{P}=0.11)$. Invasive cancer grade 3 average $\mathrm{T} / \mathrm{N}$ value $2.89 \pm 0.89$ is greater than that of grade $2 \mathrm{~T} / \mathrm{N}$ value of $2.38 \pm 0.80$; and the difference between two have statistical significance. However, the $\mathrm{T} / \mathrm{N}$ differences between grade 1 and grade 2 have no statistical significance $(\mathrm{t}=0.12, \mathrm{P}=0.89)$. Similarly, the $\mathrm{T} / \mathrm{N}$ differences between grade 1 and grade 3 also have no statistical significance $(\mathrm{t}=1.56, \mathrm{P}=0.12)$.

The prognosis of patient and treatment selection is closely related with tumor invasiveness. Generally, prognosis for invasive carcinomas is poor than ductal carcinoma in situ. In this study, the mean $\mathrm{T} / \mathrm{N}$ value for invasive cancer is $2.67+-0.84$, which is higher than that of non-invasive cancer $(2.09+-0.44)$, has clinical significance $(\mathrm{P}<0.001)$. Therefore, it suggests that breast carcinomas with higher $\mathrm{T} / \mathrm{N}$ ratio, might have poor prognosis.

In conclusion, our study suggests that $\mathrm{T} / \mathrm{N}$ value can reflect tumor size, grade, and invasiveness; and at certain level can be helpful to determine patient's prognosis. Also breast carcinomas uptake of Tc-99m-MIBI radiotracer can be correlated with these clinicopathologic parameters.

\section{Reference:}

1. Forouzanfar $\mathrm{MH}$, Foreman KJ, Delossantos AM, Lozano R, Lopez AD, Murray CJ, Naghavi M. Breast and cervical cancer in 187 countries between 1980 and 2010: a systematic analysis. Lancet. 2011 Oct 22;378(9801):1461-84. doi: 10.1016/S01406736(11)61351-2. Epub 2011 Sep 14. Review.PMID: 21924486

2. Berry DA, Cronin KA, Plevritis SK, Fryback DG, Clarke L, Zelen M, et al. Effect of screening and adjuvant therapy on mortality from breast cancer. N Engl J Med. 2005;353(17):1784-92. doi:10.1056/ NEJMoa050518.

3. Khalkhali I, Mena I, Diggles L. Review of imaging techniques for the diagnosis of breast cancer: a new role of prone scintimammography using technetium99m sestamibi. Eur J Nucl Med. 1994 Apr;21(4):357- 
62. Review.PMID: 8005161

4. Burstein HJ, Polyak K, Wong JS, et al. Ductal carcinoma in situ of the breast. N Engl J Med 2004; 350:1430-1441.

5. Spanu A, Sanna D et al. Breast scintigraphy with breast-specific $\gamma$-camera in the detection of ductal carcinoma in situ: a correlation with mammography and histologic subtype. J Nucl Med. 2012 Oct;53(10):1528-33. doi: 10.2967/ jnumed.112.103010. Epub 2012 Aug 21.

6. Chan HP, Wei J, Sahiner B, Rafferty EA, Wu T, Roubidoux $\mathrm{M}$, et al. Computer-aided detection system for breast masses on digital tomosynthesis mammograms: preliminary experience. Radiology 2005;237(3):1075-1080.

7. Kolb TM, Lichy J, Newhouse JH. Comparison of the performance of screening mammography, phys- ical examination, and breast US and evaluation of factors that influence them: an analysis of 27,825 patient evaluations. Radiology 2002; 225: 165-175.

8. Brem RF. The future of breast cancer diagnosis: molecular breast imaging. Mayo Clin Proc 2005; 80:17-18.

9. Berg WA, Zhang Z, Lehrer D, et al.; ACRIN 6666 Investigators. Detection of breast cancer with addition of annual screening ultrasound or a single screening MRI to mammography in women with elevated breast cancer risk. JAMA 2012; 307:13941404

10. Papantoniou VJ, Souvatzoglou MA, Valotassiou VJ. Relationship of cell proliferation (Ki-67) to 99mTc(V)DMSA uptake in breast cancer. Breast Cancer Res. 2004;6(2):R56-62. Epub 2003 Dec 11.

11. Cwikla JB, Buscombe JR, Kolasinska AD, Parbhoo SP, Thakrar DS, Hilson AJ. Correlation between uptake of Tc-99m sestaMIBI and prognostic factors of breast cancer. Anticancer Res. 1999 MayJun;19(3B):2299-304.PMID: 10472348.
12. Tadwalkar RV, Rapelyea JA, Torrente J, et al. Breastspecific gamma imaging as an adjunct modality for the diagnosis of invasive breast cancer with correlation to tumour size and grade. Br J Radiol 2012; 85:e212-e216

13. Zhou M, Johnson N, Gruner S, et al. Clinical utility of breast-specific gamma imaging for evaluating disease extent in the newly diagnosed breast cancer patient. Am J Surg 2009;197:159-63.

14. Kim SJ1, Kim IJ, Bae YT et al. Comparison of quantitative and visual analysis of Tc-99m MIBI scintimammography for detection of primary breast cancer. Eur J Radiol. 2005 Feb;53(2):192-8.

15. Goldsmith SJ, Parsons W, Guiberteau MJ, et al. SNM practice guideline for breast scintigraphy with breastspecific gamma cameras 1.0(J). J Nucl Med Technol, 2010, 38:219-224.

16. Orazio Schillaci1, John R. Buscombe et al. Breast scintigraphy today: indications and limitations. Eur J Nucl Med Mol Imaging (2004) 31 (Suppl. 1): S35-S45 DOI 10.1007/s00259-004-1525-x

17. Rachel F. Brem, MD, Ivan Petrovitch, MD, et al., Breast-Specific Gamma Imaging with 99mTcSestamibi and Magnetic Resonance Imaging in the Diagnosis of Breast Cancer-A Comparative Study. 2007 Blackwell Publishing, Inc., 1075-122X/07 18. Brem RF, Schoonjans JM, Kieper DA, Majewski S, Good- man S, Civelek C. High-resolution scintimammography: a pilot study. J Nucl Med 2002;43:909-15.

19. O'Connor MK, Hruska CB et al. Factors influencing the uptake of $99 \mathrm{mTc}$-sestamibi in breast tissue on molecular breast imaging. J Nucl Med Technol. 2015 Mar;43(1):13-20. doi: 10.2967/jnmt.114.150128. Epub 2015 Jan 22.PMID: 25613340.

20. Melloul M, Paz A, Ohana G et al. Double-phase 99mTc-sestamibi scintimammography and transscan in diagnosing breast cancer. J Nucl Med. 1999 Mar;40(3):376-80.PMID: 1008669 